\title{
Uni-Taschenbücher 1280
}

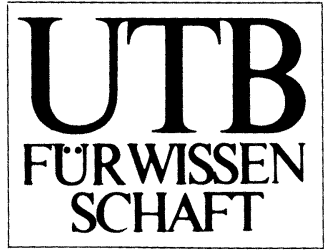

Eine Arbeitsgemeinschaft der Verlage

Birkhäuser Verlag Basel · Boston · Stuttgart

Wilhelm Fink Verlag München

Gustav Fischer Verlag Stuttgart

Francke Verlag München

Harper \& Row New York

Paul Haupt Verlag Bern und Stuttgart

Dr. Alfred Hüthig Verlag Heidelberg

Leske Verlag + Budrich GmbH Opladen

J. C. B. Mohr (Paul Siebeck) Tübingen

R.v. Decker \& C. F. Müller Verlagsgesellschaft m. b. H. Heidelberg Quelle \& Meyer Heidelberg

Ernst Reinhardt Verlag München und Basel

K. G. Saur München $\cdot$ New York $\cdot$ London $\cdot$ Paris

F. K. Schattauer Verlag Stuttgart $\cdot$ New York

Ferdinand Schöningh Verlag Paderborn $\cdot$ München $\cdot$ Wien $\cdot$ Zürich

Eugen Ulmer Verlag Stuttgart

Vandenhoeck \& Ruprecht in Göttingen und Zürich 


\section{Wolfgang Rudzio \\ Das politische System \\ der Bundesrepublik Deutschland}


Wolfgang Rudzio

\section{Das politische System der Bundesrepublik Deutschland}

Eine Einführung

Leske Verlag + Budrich GmbH, Opladen 


\section{Der Autor}

Wolfgang Rudzio, geb. 1935, Staatsexamen in Mathematik und Geschichte 1963, Promotion zum Dr. phil. 1967, Professor fur Politikwissenschaft 1972 73 an der Universität Frankfurt, seitdem an der Universität Oldenburg.

Veröffentlichungen: Die Neuordnung des Kommunalwesens in der Britischen Zone, Stuttgart 1968; Die organisierte Demokratie, Stuttgart 1977 (2.A.1982); Der Marsch der DKP durch die Institutionen, Frankfurt 1980 (Koautor). Daneben Buchbeiträge und Aufsätze insbes. zur Sozialisierungsfrage nach 1945, zur Rolle von Koalitionsausschüssen, zur DKP- und zur Kommunalpolitik.

Sonderauflage für die Landeszentrale für politische Bildungsarbeit Berlin

\section{CIP-Kurztitelaufnahme der Deutschen Bibliothek}

\section{Rudzio, Wolfgang}

Das politische System der Bundesrepublik Deutschland:

e. Einf./Wolfgang Rudzio. - Opladen: Leske und Budrich, 1983

(UTB für Wissenschaft: Uni Taschenbücher 1280)

ISBN 978-3-8100-0429-1

DOI 10.1007/978-3-322-85267-0

ISBN 978-3-322-85267-0 (eBook)

NE: UTB für Wissenschaft/Uni Taschenbücher

(C) by Leske Verlag + Budrich GmbH, Opladen 1983

Einbandgestaltung: A. Krugmann, Stuttgart 


\section{Inhalt}

Abkürzungsverzeichnis . . . . . . . . . . . . . 9

Einleitung ................... 11

A Die Staatsräson der Bundesrepublik $\ldots \ldots \ldots \ldots \ldots 13$

1. Die antitotalitäre Demokratie des Grundgesetzes . . . . . 15

1.1 Zur Entstehungsgeschichte des Grundgesetzes . . . . . 15

1.2 Die zentralen Verfassungsprinzipien . . . . . . . . 23

1.3 Wehrhafte Demokratie als Fazit der Geschichte . . . . . 30

2. Westbindung als außenpolitische Grundentscheidung . . . 35

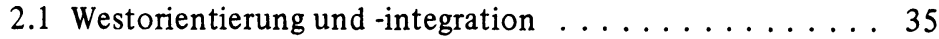

2.2 Exponierte Lage und Abhängigkeit . . . . . . . . . 39

2.3 Vom deutschen Sonderkonflikt zur Ostpolitik . . . . . . 43

B Das politische Kräftefeld . . . . . . . . . . . . . . . . . . 49

3. Sozio-ökonomische Probleme und Interessenlagen . . . . . 51

3.1 Demographischer Wandel und seine Folgen . . . . . . . . 51

3.2 Wirtschaftliche Entwicklungen und Probleme . . . . . . . 53

3.3 Soziale Strukturen . . . . . . . . . . . . . 57

4. Organisierte Interessen im politischen Prozeß . . . . . . 66

4.1 Interessenpluralismus in der Demokratie . . . . . . . 66

4.2 Das Spektrum der organisierten Interessen . . . . . . . . 69

4.3 Binnensoziologie der Interessenorganisationen . . . . . 81

4.4 Verbandseinfluß im politischen Prozeß . . . . . . . . 86

4.5 Korporatistische Strukturen . . . . . . . . . . . . 97

5. Das Parteiensystem . . . . . . . . . . . . . . 102

5.1 Die Reichweite der Parteiendemokratie . . . . . . . . . 102

5.2 Wandlungen des Parteiensystems . . . . . . . . . 110

5.3 Programmatische Dimensionen des Parteiensystems . . . . 124

5.4 Parteienfinanzierung . . . . . . . . . . . . 134

6. Binnenstrukturen der Parteien . . . . . . . . . . . . 144

6.1 Die formale Organisation der Parteien . . . . . . . . . . 144 
6.2 Die Praxis innerparteilicher Willensbildung . . . . . 150

6.3 Die Parteimitglieder - Schlagseiten der Partizipation . . . 155

7. Strukturen des Wählerverhaltens . . . . . . . . . . 162

7.1 Wahlrecht und Wahlbeteiligung . . . . . . . . . 162

7.2 Schicht- und Konfessionswahl . . . . . . . . . . . 166

7.3 Aktuelle Situation und Wahlverhalten . . . . . . . . 176

8. Die Medien als Mittler und Akteure . . . . . . . . . . . 183

8.1 Demokratie und Massenkommunikation . . . . . . 183

8.2 Die duale Struktur des Mediensystems . . . . . . 187

8.3 Funktionsprobleme der Medien . . . . . . . . . . 193

C Die politischen Institutionen . . . . . . . . . . . 201

9. Im Zentrum des Entscheidungssystems: Der Bundestag . . 205

9.1 Der Dualismus von Mehrheit und Opposition . . . . . . 205

9.2 Die Organisation des Fraktionenparlaments . . . . . . 210

9.3 Die Wahlfunktion: Legitimierende Mehrheitsbildung . . . 220

9.4 Kontrollfunktion und Mitregierung . . . . . . . . 225

9.5 Legislative Funktionen: Zwischen Rede- und Arbeitsparlament . . . . . . . . . . . . . 230

10. Die Bundesregierung als Führungsorgan . . . . . . . . 242

10.1 Prinzipien der Kabinettsstruktur . . . . . . . . . . . 242

10.2 Die Ministerialorganisation . . . . . . . . . . 250

10.3 Die Grenzen des Kabinetts als Entscheidungszentrum . . 258

11. Gegengewichte im Bund . . . . . . . . . . . . . 266

11.1 Der Bundesrat: Mehr als Vertretung der Länderinteressen? . . . . . . . . . . . . . . 266

11.2 Die Bundesbank: Wirtschaftspolitische Nebenregierung? . . . . . . . . . . . . . . . . . . 275

11.3 Das Bundesverfassungsgericht: Hüter und Interpret der Verfassung . . . . . . . . . . . . . . . . . 276

11.4 Der Bundespräsident: Mehr als nur Repräsentant? . . . . . 285

12. Machtverteilender Föderalismus . . . . . . . . . . 293

12.1 Bundesländer und Länderparlamentarismus . . . . . . . . 293

12.2 Die Politikverflechtung zwischen Bund und Ländern . . . 300

12.3 Praxis und Probleme des kooperativen Föderalismus . . . . 309

13. Die Kommunen zwischen Politik und Verwaltung . . . . . 313

13.1 Die kommunale Demokratie . . . . . . . . . . . . 313

13.2 Gegenstandsfeld und Rahmenbedingungen kommunaler Politik . . . . . . . . . . . . . . . 327 
D Die Reichweite des politischen Systems . . . . . . . . 337

14. Handlungsfelder der Politik . . . . . . . . . . . . . . 339

14.1 Ordnungs- und Sicherheitspolitik . . . . . . . . . . . . 339

14.2 Sozio-ökonomische Politikfelder . . . . . . . . . . . . . 344

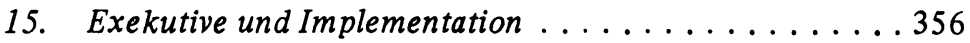

15.1 Strukturen des öffentlichen Dienstes . . . . . . 356

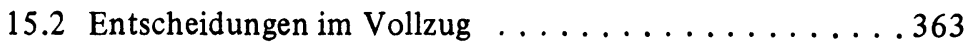

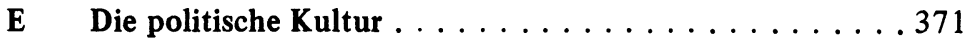

16. Politische Elite: Auf dem Wege zur politischen Klasse? . . . . . . . . . . . . . . . . . . . 373

16.1 Strukturen der politischen Elite . . . . . . . . . . . 373

16.2 Politische Einstellungen der Eliten . . . . . . . . . . 384

17. Einstellungen zum politischen System . . . . . . . . . . 389

17.1 Der Weg in die Normalität westlicher Demokratien . . . . 389

17.2 Indikatoren der Verunsicherung . . . . . . . . 400

Sachregister . . . . . . . . . . . . . . . . . 412

Personenregister . . . . . . . . . . . . . . . . 419 


$\begin{array}{ll}\text { ADAC } & \text { Allgemeiner Deutscher Automobil-Club } \\ \text { ARD } & \text { Arbeitsgemeinschaft der Rundfunkanstalten Deutschlands } \\ \text { Art. } & \text { Artikel } \\ \text { BBC } & \text { British Broadcasting Company } \\ \text { BDI } & \text { Bundesverband der Deutschen Industrie } \\ \text { BHE } & \text { Block der Heimatvertriebenen und Entrechteten } \\ \text { BP } & \text { Bayernpartei } \\ \text { BVerfGE } & \text { Entscheidungen des Bundesverfassungsgerichts } \\ \text { BVP } & \text { Bayerische Vokspartei } \\ \text { CDU } & \text { Christlich-Demokratische Union } \\ \text { CGB } & \text { Christlicher Gewerkschaftsbund } \\ \text { CSU } & \text { Christlich-Soziale Union } \\ \text { DAG } & \text { Deutsche Angestelltengewerkschaft } \\ \text { DAK } & \text { Deutsche Angestellten-Krankenkasse } \\ \text { DDP } & \text { Deutsche Demokratische Partei } \\ \text { DDR } & \text { Deutsche Demokratische Republik } \\ \text { DFU } & \text { Deutsche Friedensunion } \\ \text { DGB } & \text { Deutscher Gewerkschaftsbund } \\ \text { Diss. } & \text { Dissertation } \\ \text { DIW } & \text { Deutsches Institut für Wirtschaftsforschung } \\ \text { DKP } & \text { Deutsche Kommunistische Partei } \\ \text { DNVP } & \text { Deutschnationale Volkspartei } \\ \text { DReP } & \text { Deutsche Rechtspartei } \\ \text { DRP } & \text { Deutsche Reichspartei } \\ \text { EG } & \text { Europäische Gemeinschaft(en) } \\ \text { EVG } & \text { Europäische Verteidigungsgemeinschaft } \\ \text { FAZ } & \text { Frankfurter Allgemeine Zeitung } \\ \text { FDP } & \text { Freie Demokratische Partei } \\ \text { FR } & \text { Frankfurter Rundschau } \\ \text { GDP } & \text { Gesamtdeutsche Partei } \\ \text { GG } & \text { Grundgesetz } \\ \text { GVP } & \text { Gesamtdeutsche Volkspartei } \\ \text { i.e.S. } & \text { im engeren Sinne } \\ \text { IG } & \text { Industriegewerkschaft } \\ \text { IHK } & \text { Industrie- und Handelskammer } \\ \text { k.A. } & \text { keine Angabe } \\ \text { KP } & \text { Kommunistische Partei } \\ \text { KPD } & \text { Kommunistische Partei Deutschlands } \\ \text { KPD/ML } & \text { Kommunistische Partei Deutschlands/Marxisten-Leninister } \\ \text { KZSS } & \text { Kölner Zeitschrift für Soziologie und Sozialpsychologie } \\ \text { LAG } & \text { Lastenausgleichsgesetz } \\ \text { MLF } & \text { Multilateral Force } \\ \text { N } & \text { Number (Zahl) } \\ \text { NATO } & \text { North Atlantic Treaty Organisation } \\ \text { NDR } & \text { Norddeutscher Rundfunk } \\ \text { NG } & \text { Nationale Gemeinschaft } \\ \text { NLP } & \text { Niedersächsische Landespartei } \\ \text { NPD } & \text { Nationaldemokratische Partei Deutschlands } \\ & \end{array}$




$\begin{array}{ll}\text { NRW } & \text { Nordrhein-Westfalen } \\ \text { NSDAP } & \text { Nationalsozialistische Deutsche Arbeiterpartei } \\ \text { NS } & \text { Nationalsozialistisch } \\ \text { ÖTV } & \text { Gewerkschaft Öffentliche Dienste, Transport und Verkehr } \\ \text { PVS } & \text { Politische Vierteljahresschrift } \\ \text { SA } & \text { Sturmabteilungen } \\ \text { SED } & \text { Sozialistische Einheitspartei Deutschlands } \\ \text { SKE } & \text { Steinkohle-Einheiten } \\ \text { SPD } & \text { Sozialdemokratische Partei Deutschlands } \\ \text { SRP } & \text { Sozialistische Reichspartei } \\ \text { SSW } & \text { Südschleswigscher Wählerverband } \\ \text { StGB } & \text { Strafgesetzbuch } \\ \text { ULA } & \text { Union Leitender Angestellter } \\ \text { UdSSR } & \text { Union der Sozialist. Sowjetrepubliken } \\ \text { USA } & \text { United States of America } \\ \text { WAV } & \text { Wirtschaftliche Aufbau-Vereinigung } \\ \text { WDR } & \text { Westdeutscher Rundfunk } \\ \text { WRV } & \text { Weimarer Reichsverfassung } \\ \text { Z } & \text { Zentrum } \\ \text { ZDF } & \text { Zweites Deutsches Fernsehen } \\ \text { ZfP } & \text { Zeitschrift für Politik } \\ \text { ZParl } & \text { Zeitschrift für Parlamentsfragen }\end{array}$

